Full-text Available Online at www.ajol.info and www.bioline.org.br/ja
J. Appl. Sci. Environ. Manage. June, 2015

Vol. 19 (2) 279- 288

\title{
Adsorption of Crystal Violet onto Adsorbents Derived from Agricultural Wastes: Kinetic and Equilibrium Studies
}

\author{
*AKINOLA, LK; UMAR, AM \\ ${ }^{1}$ Department of Chemistry, Faculty of Science, Bauchi State University, Gadau, Nigeria \\ ${ }^{2}$ Department of Soil Science, Faculty of Agriculture, Bayero University Kano, Nigeria \\ ["Corresponding Author, e-mail: lukman.akinola@yahoo.com Telephone: +2348039690371]
}

\begin{abstract}
Suitability of adsorbents derived from groundnut shell (GS) and bean pod (BP) in removing crystal violet from aqueous solution was evaluated in a series of batch experiments. Findings reveal that the points of zero charge (PZC) of GS and BP are 3.50 and 3.00 respectively. Findings also show that GS and BP exhibit maxima adsorption at $\mathrm{pH}$ values of 6.00 and 5.00 respectively. For both GS and BP, pseudo-second order model gives the best fit for the sorption kinetic data while Freundlich isotherm gives the best fit for the sorption equilibrium data. These findings suggest that the adsorption of crystal violent onto GS and BP probably involves chemisorption and the adsorption does not reach a plateau as the concentration of crystal violet in the aqueous solution increases. This study demonstrates the suitability of GS and BP as low-cost adsorbents for removing crystal violet from industrial wastewater. (C) JASEM
\end{abstract}

\section{http://dx.doi.org/10.4314/jasem.v19i2.15}

KEYWORDS: Adsorption, Bean pod, Crystal violet, Equilibrium, Groundnut shell, Kinetics

\section{INTRODUCTION}

Many industries, such as dyestuff, textile, pharmaceutical, paper, plastic, and tannery, make use of dyes to color their products. Of these industries, textile industry is the largest consumer of dyes. It has been shown that about 10,000 different textile dyes with an estimated annual production of $7 \times 10^{5}$ metric tons are commercially available worldwide (Carmen and Daniela, 2012). As a result of the enormous utilization of these dyes, substantial amount of dyes are frequently released as wastewater into aquatic environment. In recent time, there is a growing interest and concern over contamination of the aquatic environment by dyes. This is because the release of dyes into aquatic environment causes reduction in the growth of algae due to obstruction of light required for photosynthesis, which subsequently leads to ecological imbalance in the aquatic ecosystem (de Sousa et al, 2012). Contamination of aquatic environment by dyes has also been shown to have toxic, carcinogenic, and aesthetic effects on humans (Ratna and Pahdi, 2012).

Crystal violet, also known as gentian violet, is a triarylmethane dye. Medically, the dye is used as an antiseptic with a selective action on gram-positive organisms. It is also used for the treatment of burns, boils, carbuncles, and mycotic skin infections (The Council of Pharmaceutical Society of Great Britain,
1973). Due to the deleterious effects of dyes on aquatic ecosystem, different approaches have been proposed for the removal of dyes in contaminated effluents. These methods can broadly be classified as biological, chemical and physical (Adinew, 2012). Specifically, decolourization, degradation or removal of crystal violent from aqueous solution has been investigated using biodegradation methods (Azmi et al, 1998; Oranusi and Ogugbue, 2005; ZablockaGodlewska et al, 2009; Thorat and Sayyad, 2010; Gursahani and Gupta, 2011; Tom-Sinoy et al, 2011; Kunjadia et al, 2012), methods involving chemical reaction (Mohammed et al, 2011; Patil, 2011; Su and Wang, 2011; Fayoumi et al, 2012; Ovejero et al, 2012) and adsorption methods (Chen et al, 2011; Lin et al, 2011; Nidheesh et al, 2011; Patil et al, 2011; Rammel et al, 2011; Gandhimathi et al, 2012; Nidheesh et al, 2012a; Pandian et al, 2012; Patil and Shrivastava, 2012; Prasad and Santhi, 2012; Shouman et al, 2012). Among these three approaches, adsorption is the preferred method because it does not leave any toxic residue behind in the treated water.

Although adsorption by activated carbon is considered to be very effective in removing dyes from contaminated water, the cost of activated carbon and the difficulty associated with its regeneration impose a serious restriction on its routine use as adsorbent (Allen and Koumanova, 2005; Bhatnagar and 
Minocha, 2006; Foo and Hameed, 2010; Grassi et al, 2012). Recently, efforts are being made worldwide to invent more effective, low cost, environmental friendly and easily regenerated adsorbents from agricultural wastes (Mahmoud et al, 2012; Sharma et al, 2012; Rashed, 2013). It is in view of this current global endeavor that the present study aims at investigating the kinetics and equilibrium isotherms of groundnut shells and bean pods as low cost adsorbents for the removal of crystal violet from aqueous solution.

\section{MATERIALS AND METHODS}

\section{Collection and Preparation of Adsorbents:} Groundnut shells and bean pods were collected from agricultural wastes disposed of by subsistent farmers during harvest period. The shells and the pods were washed, dried, ground and sieved as described elsewhere (Ajmal et al, 2006; Gong et al, 2011; Choudhury et al, 2012; and Kiran et al, 2013). The adsorbents were sieved through a mesh with a pore size of $2 \mathrm{~mm}$. Hence, all the adsorbents with particle size with diameter in the range of $\leq 2 \mathrm{~mm}$ were used in this study. The fine particles prepared from Groundnut Shells and Bean Pods were stored in clean, dried, air-tight containers and were labeled GS and $\mathrm{BP}$ respectively.

Determination of Points of Zero Charge of the Adsorbents: Point of zero charge (PZC) has been defined as the $\mathrm{pH}$ value for which the surface charge of a material is equal to zero at some ambient temperature, applied pressure, and aqueous solution composition (Sposito, 2004). The points of zero charge of GS and BP were determined using solid addition method (Nidheesh et al, 2012b). In this method, $50 \mathrm{~mL}$ of solution containing $0.1 \mathrm{~mol} / \mathrm{L}$ of $\mathrm{NaNO}_{3}$ was transferred into twelve $250 \mathrm{~mL}$ Erlenmeyer flasks. The $\mathrm{pH}$ of each solution was adjusted to values ranging from 1.00 to 12.00 by adding an appropriate amount of $1.0 \mathrm{~mol} / \mathrm{L} \mathrm{HNO}_{3}$ or $1.0 \mathrm{~mol} / \mathrm{L} \mathrm{NaOH}$ solution before the final volume was made up to $50 \mathrm{~mL}$ with distilled water. Thereafter, 1.0 $\mathrm{g}$ of GS was added to each flask and the final $\mathrm{pH}$ of the supernatants measured using JENWAY $3505 \mathrm{pH}$ meter after agitating the flasks at $200 \mathrm{rpm}$ for 5 hours. The difference between the initial and the final $\mathrm{pH}$ was calculated using equation (1). A plot of $\Delta p H$ against $p H_{i}$ was constructed and the point of interception on the $p H_{i}$ axis gave the value of PZC for GC. The values of PZC for BP was similarly determined as described above for GS. $\Delta p H=p H_{f}-$ $p H_{i}$ (1) Where $p H_{i}$ is the initial $p H, p H_{f}$ is the final $p H$ and $\Delta p H$ is the difference between initial and final $p H$.
Preparation of Adsorbate Solutions: Crystal violet and other reagents were purchased from Zayo-Sigma Chemicals Ltd, Jos, Nigeria and were used without further purification. All the reagents used were of analytical grade. A stock solution containing 1000 $\mathrm{mg} / \mathrm{L}$ of crystal violet was prepared by dissolving 1.0 $\mathrm{g}$ of the dye in $500 \mathrm{~mL}$ distilled water. The resulting solution was transferred into $1 \mathrm{~L}$ volumetric flask and then diluted to volume with distilled water. Other working solutions with concentrations of crystal violet ranging from $25 \mathrm{mg} / \mathrm{L}$ to $200 \mathrm{mg} / \mathrm{L}$ were prepared from the stock solution by serial dilution in $100 \mathrm{~mL}$ volumetric flasks. The $\mathrm{pH}$ and ionic strength of the working solutions were adjusted to the required $\mathrm{pH}$ and ionic strength by adding appropriate amounts of $1.0 \mathrm{~mol} / \mathrm{L} \mathrm{HNO}_{3}$ solution and $1.0 \mathrm{~mol} / \mathrm{L} \mathrm{NaNO}_{3}$ solution. All pH measurements were made using JENWAY 3505 pH meter.

Batch Experiment for Determining the Effects of $p H$ on Removal Efficiency To investigate the effect of $\mathrm{pH}$ on the adsorption of crystal violet onto GS, $1.0 \mathrm{~g}$ of the adsorbent was added separately into seven 250 $\mathrm{mL}$ Erlenmeyer flasks. Thereafter, $50 \mathrm{~mL}$ of crystal violet (concentration $=100 \mathrm{mg} / \mathrm{L}$ ) solution, maintained at constant ionic strength of $0.1 \mathrm{~mol} / \mathrm{L}$, was then transferred into each flask. The $\mathrm{pH}$ of each flask was adjusted to values ranging from 1.00 to 7.00 by adding appropriate amount of $1.0 \mathrm{~mol} / \mathrm{L} \quad \mathrm{HNO}_{3}$ solution. This investigation was not carried out at $\mathrm{pH}$ values above 7.00 because decolorization of crystal violet occurs in alkaline medium. The flasks were then agitated in a batch experiment using Orbital Shaker WSZ Series at $200 \mathrm{rpm}$ at ambient temperature $\left(28 \pm 1{ }^{0} \mathrm{C}\right)$ for 24 hours. All the 7 samples were later centrifuged and the equilibrium concentrations of crystal violent in the supernatants determined spectrophotometrically using UNICO UV-2100 Spectrophotometer. The removal efficiency (expressed as sorption percent) of crystal violet by GS was calculated using equation (2). The experiment described above was carried out twice and the average values of the data obtained were used to make plots of sorption percent against $\mathrm{pH}$. The procedure described above was repeated using $\mathrm{BP}$ in place of GS.Sorption (\%) $=\left(\frac{C_{i}-C_{e}}{C_{i}}\right) \times 100$ (2) Where $C_{i}$ is the initial concentration (measured in $\mathrm{mg} / \mathrm{L}$ ) of crystal violet in solution and $C_{e}$ is the residual concentration (measured in $\mathrm{mg} / \mathrm{L}$ ) of crystal violet in solution at equilibrium

Batch Experiment for Investigating Sorption Kinetics: Kinetics of crystal violet adsorption onto GS was investigated in a batch experiment by adding $1.0 \mathrm{~g}$ of GS into nine $250 \mathrm{~mL}$ Erlenmeyer flasks containing 50 
$\mathrm{mL}$ of the dye solution each. The concentration of crystal violet in each flask was $50 \mathrm{mg} / \mathrm{L}$. The content of each flask was maintained at constant ionic strength of $0.1 \mathrm{~mol} / \mathrm{L}$ and the optimum $\mathrm{pH}$, as determined in the experiment described in the preceding section. Each flask was then agitated using Orbital Shaker WSZ Series at $200 \mathrm{rpm}$ at ambient temperature $\left(28 \pm 1{ }^{\circ} \mathrm{C}\right)$ for $20,40,60,80,100,120$, 140,160 , or 180 minutes. The samples were then centrifuged and the concentrations of crystal violent remaining in the supernatants were determined spectrophotometrically at $590 \mathrm{~nm}$ using UNICO UV2100 Spectrophotometer. The amount of crystal violet adsorbed on the adsorbent at any given time is calculated using equation (3). This experiment was carried out twice and the fitness of the average data obtained was tested using intraparticle diffusion model (equation 4), pseudo-first order model (equation 5) and pseudo-second order model (equation 6). The procedure described above was repeated using BP in place of GS. $q_{t}=\frac{V}{m}\left(C_{i}-C_{t}\right)$. (3) $q_{t}=k_{\text {int }} t^{1 / 2}$ (4) ; $\log \left(q_{e}-q_{t}\right)=\log q_{e}-$ $\frac{k_{1}}{2.303} \mathrm{t} \ldots \ldots \frac{t}{q_{t}}=\frac{1}{k_{2} q_{e}^{2}}+\frac{1}{q_{e}} t \quad(6)$, Where $q_{t}$ is the amount of crystal violet adsorbed on the adsorbent (measured in $\mathrm{mg} / \mathrm{g}$ ) at any given time, $q_{e}$ is the amount of crystal violet adsorbed on the adsorbent (measured in $\mathrm{mg} / \mathrm{g}$ ) at equilibrium, $C_{i}$ is the initial concentration of crystal violent in solution (measured in $\mathrm{mg} / \mathrm{L}), C_{t}$ is the residual concentration of crystal violet in solution at time $\mathrm{t}, \mathrm{V}$ is the volume of crystal violent solution (measured in $\mathrm{L}$ ), $\mathrm{m}$ is the mass of adsorbent (measured in $\mathrm{g}$ ), $\mathrm{t}$ is time (measured in minutes), $k_{1}$ is pseudo-first order rate constant, $k_{2}$ is pseudo-second order rate constant, and $k_{\text {int }}$ is intraparticle diffusion rate constant

Batch Experiment for Investigating Equilibrium Isotherms: Sorption isotherm study was investigated by adding $1.0 \mathrm{~g}$ of GS to eight $250 \mathrm{~mL}$ Erlenmeyer flask, containing $50 \mathrm{~mL}$ of dye solution each. The concentrations of crystal violet in the flasks ranged from $25 \mathrm{mg} / \mathrm{L}$ to $200 \mathrm{mg} / \mathrm{L}$ (that is, $25,50,75,100$, $125,150,175$ and $200 \mathrm{mg} / \mathrm{L}$ crystal violet). The content of each flask was maintained at constant ionic strength of $0.1 \mathrm{~mol} / \mathrm{L}$ and the optimum $\mathrm{pH}$ determined in the previous experiment. Each flask was agitated using Orbital Shaker WSZ Series at $200 \mathrm{rpm}$ at ambient temperature $\left(28 \pm 1{ }^{0} \mathrm{C}\right)$ for 24 hours, centrifuged and the equilibrium concentrations of crystal violent in the supernatants determined spectrophotometrically at $590 \mathrm{~nm}$ using UNICO UV2100 Spectrophotometer. The amount of crystal violet adsorbed onto the adsorbent at equilibrium was calculated using equation (7). This experiment was carried out twice and the fitness of the average data obtained was tested using Langmuir adsorption isotherm (equation 8), Freundlich adsorption isotherm (equation 9) and Temkin adsorption isotherm (equation 10). The procedure described above was repeated using BP in place of GS. $q_{e}=\frac{V}{m}\left(C_{i}-C_{e}\right)$ (7) $\frac{1}{q_{e}}=\frac{1}{q_{\max }}+\frac{1}{q_{\max }} b C_{e} \quad$ (8) $\ln q_{e}=\ln K_{F}+$ $\left.\frac{1}{n} \ln C_{e} \ldots 9\right) q_{e}=B_{1} \ln K_{T}+B_{1} \ln C_{e}(10)$

Where $q_{e}$ is the amount of crystal violet adsorbed on the adsorbent (measured in $\mathrm{mg} / \mathrm{g}$ ) at equilibrium, $C_{i}$ is the initial concentration of crystal violent in solution (measured in $\mathrm{mg} / \mathrm{L}$ ), $C_{e}$ is the residual concentration of crystal violet in solution at equilibrium (measured in $\mathrm{mg} / \mathrm{L}), \mathrm{V}$ is the volume of crystal violent solution (measured in L), $\mathrm{m}$ is the mass of adsorbent (measured in g), $q_{\max }$ is maximum adsorption capacity $(\mathrm{mg} / \mathrm{g}), \mathrm{b}$ is the affinity coefficient, $B_{1}$ is the maximum binding energy, $K_{T}$ is the equilibrium binding constant, $K_{F}$ is the Freundlich constant for sorption capacity, and $\mathrm{n}$ is Freundlich constant for intensity.

\section{RESULTS AND DISCUSSION}

The results for the determination of points of zero charge (PZC) of GS and BP are presented in Figure 1. As shown in the figure, the PZC values for GS and $\mathrm{BP}$ are 3.50 and 3.00 respectively. In other words, at normal atmospheric pressure, temperature of $28{ }^{0} \mathrm{C}$ and aqueous solution with ionic strength of $0.1 \mathrm{~mol} / \mathrm{L}$, the charges on the surfaces of GS and BP are equal to zero at $\mathrm{pH}$ of 3.50 and 3.00 respectively. The implication of these findings is that, at $\mathrm{pH}$ values below PZC, the surface charges on the adsorbents are positive while at $\mathrm{pH}$ values above $\mathrm{PZC}$, the surface charges of the adsorbents are negative (Oluwaseye et $a l, 2011$ and Gusmao et al, 2013). Points of zero charge reported in literature for adsorbents derived from other agricultural wastes are 7.10 for oil palm fruit fibre (Abia and Asuquo, 2008), 5.00 for sugarcane bagasse (Zhang et al, 2011), 6.00 for watermelon shell (Banerjee et al, 2012) and 4.18 for orange peel (De Souza et al, 2012)

A plot of sorption percent against $\mathrm{pH}$ is presented in Figure 2. As shown in the figure, the removal efficiencies of crystal violent from aqueous solution by both GS and $\mathrm{BP}$ are less than 50 percent at $\mathrm{pH}$ below 4.00. However, as the $\mathrm{pH}$ values of the solutions were adjusted to 4.00 and above, the removal efficiencies continue to increase, reaching a maximum value of $80.8 \%$ at $\mathrm{pH}$ of 6.00 for GS and a maximum value of $84.4 \%$ at $\mathrm{pH}$ of 5.00 for $\mathrm{BP}$. These findings can be explained using the values of PZC determined for GS and BP in the preceding paragraph. 
The higher adsorption of crystal violet by GS and BP at $\mathrm{pH}$ values above their $\mathrm{PZC}$ is to be expected because crystal violet molecules exist as positively charged ions in aqueous solution, and therefore exhibit enhanced electrostatic attraction for the adsorbents since the surface charges on the adsorbents are negative at higher $\mathrm{pH}$ values.

Figures 3, 4 and 5 are plots of intraparticle diffusion, pseudo-first order and pseudo-second order models for testing the kinetics of adsorption of crystal violet on GS. Also displayed in Figures 6, 7 and 8 are plots of intraparticle diffusion, pseudo-first order and pseudo-second order models for testing the kinetics of adsorption of crystal violet on BP. The rate constants and coefficients of determination derived from these plots are summarized in Table 1. As shown in Table 1, pseudo-second order model gives the best fit for the sorption kinetic data for both GS and BP as indicated by the values of the coefficients of determination $\left(R^{2}=0.804\right.$ for GS and $R^{2}=0.997$ for BP). The pseudo-second order rate constants for the adsorption of crystal violet onto GS and BP are $6.72 \times 10^{-3}$ and $6.05 \times 10^{-2}$ respectively (see Table 1 ). This result suggests that the rate of crystal violet adsorption onto $\mathrm{BP}$ is about nine times higher than the rate of crystal violet adsorption onto GS. Pseudo-second order model obtained in the present study agrees with previous findings reported in literature for the adsorption of crystal violent onto adsorbents derived from cocoa shell (Chinniagounder et al, 2011), mycelial biomass of Ceriporia lacerata P2 (Lin et al, 2011), Chaetophora elegans alga (Rammel et al,

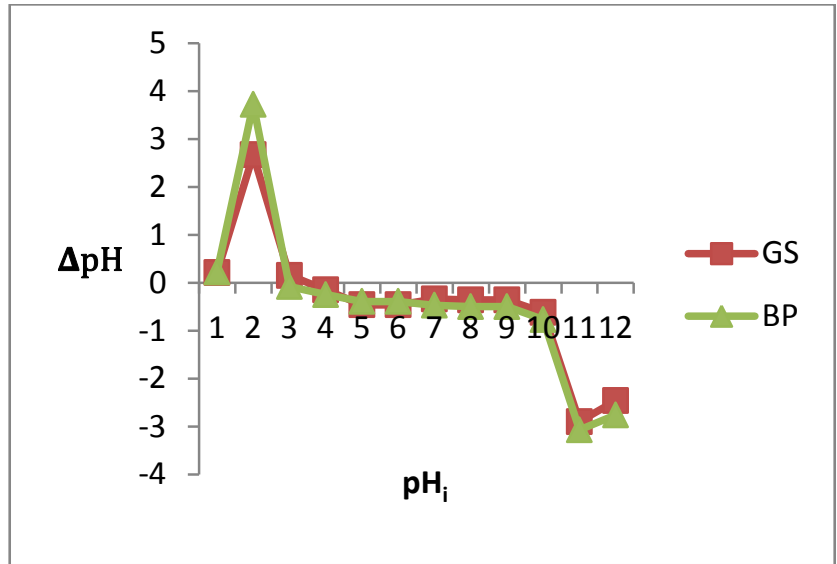

Fig 1: A plot of $\Delta p H$ against $p H_{i}$ for the determination of points of zero charge for GS and BP
2011), Leucaena leucocephala Seed Pods (Patil and Shrivastava, 2012) and Acacia nilotica Leaves (Prasad and Santhi, 2012). The pseudo-second order model, according to Ho (2006), is base on the assumption that the adsorption process involves chemisorption, which requires valence forces through the sharing or exchange of electrons between the adsorbent and the adsorbate.

The Plots displayed in Figures 9, 10 and 11 are the Langmuir, Freundlich and Temkin adsorption isotherms for testing the equilibrium data of crystal violet adsorption onto GS. Also displayed in Figures 12, 13 and 14 are plots representing Langmuir, Freundlich and Temkin adsorption isotherms for testing the equilibrium data of crystal violet adsorption onto BP. The parameters derived from these plots are summarized in Table 2. As shown in Table 2, the adsorption data fitted well with Freundlich adsorption isotherm for both GS and BP as indicated by the values of the coefficients of determination $\left(R^{2}=0.805\right.$ for GS and $R^{2}=0.886$ for $\mathrm{BP})$. These findings lend credence to the assumption behind Freundlich equation that the isotherm does not reach a plateau as the concentration of adsorbate in solution increases (Limousin et al, 2007). Adsorption isotherms of crystal violet onto adsorbent prepared from sugarcane bagasse, chitosan, cocoa shell, mangrove plant, tamarind fruit shell, mango leaf, teak tree bark and almond tree bark have been described in the literature (Chinniagounder et al, 2011; Patil et al, 2011 and Shouman et al, 2012)

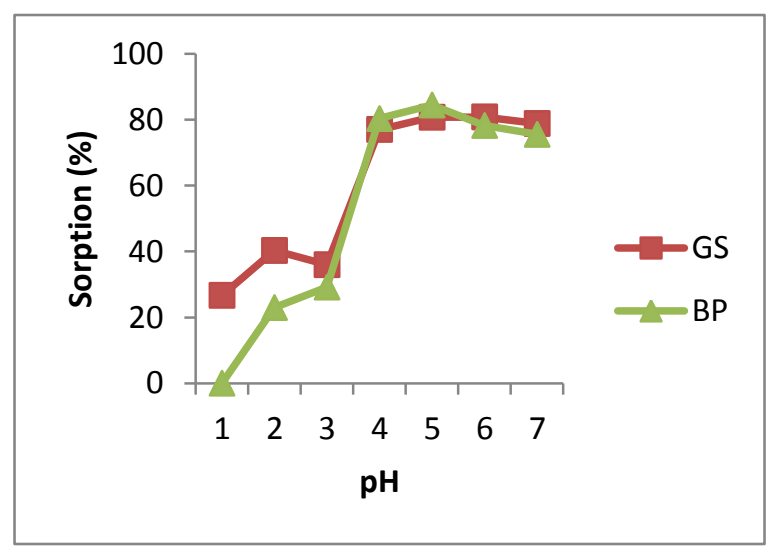

Fig 2: A plot of sorption percent against $\mathrm{pH}$ showing the effect of $\mathrm{pH}$ on removal efficiency 


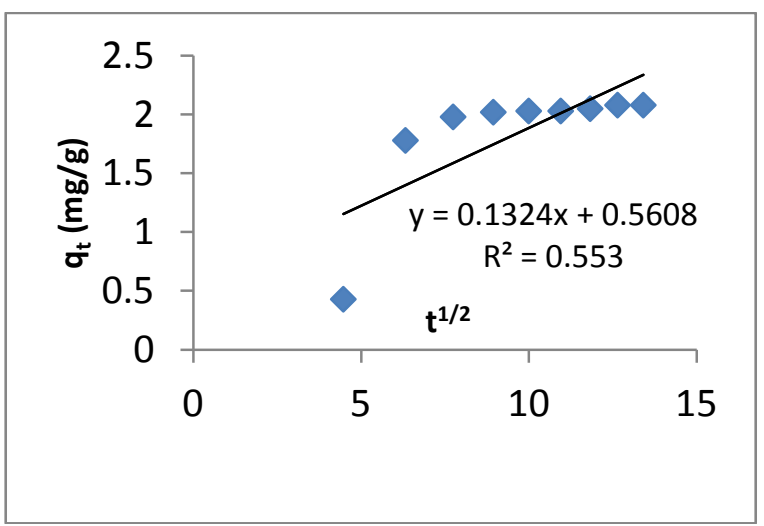

Fig 3: Intraparticle diffusion plot for the adsorption of crystal violet onto GS

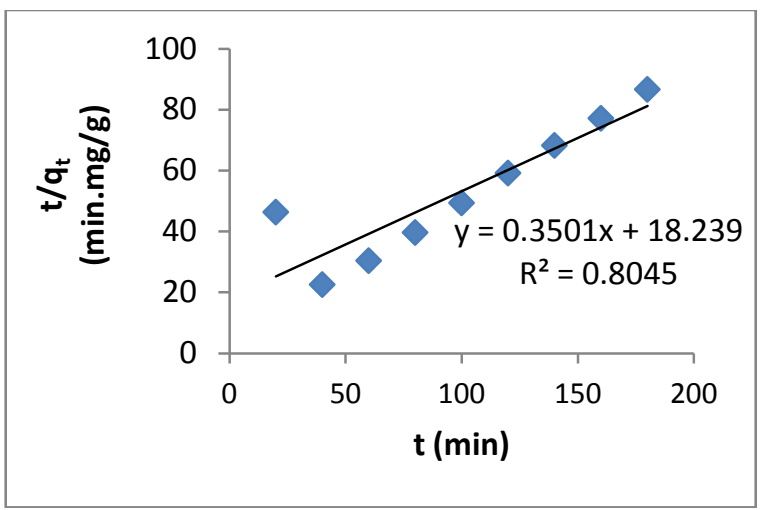

Fig 5: Pseudo-second order kinetic plot for the adsorption of crystal violet onto GS

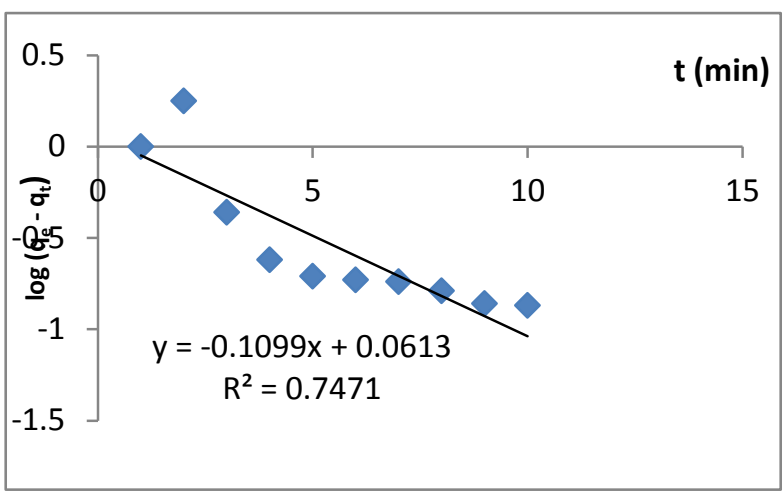

Fig 4: Pseudo-first order kinetic plot for the adsorption of crystal violet onto GS

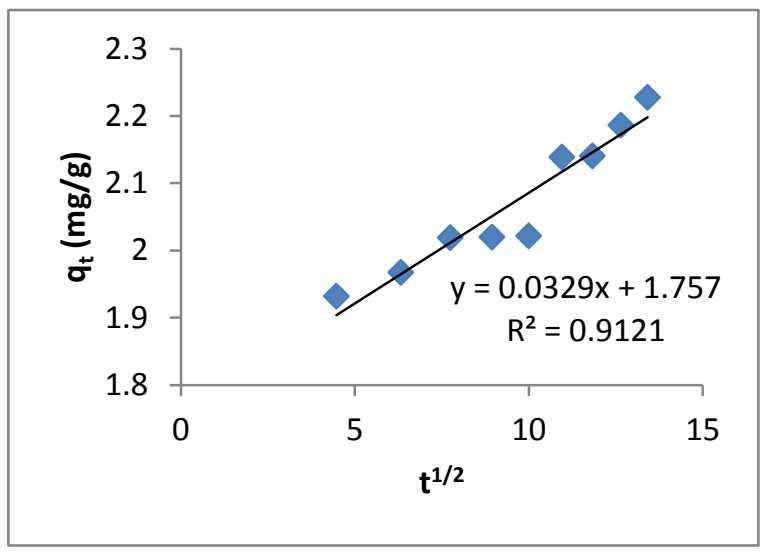

Fig 6: Intraparticle diffusion plot for the adsorption of crystal violet onto BP

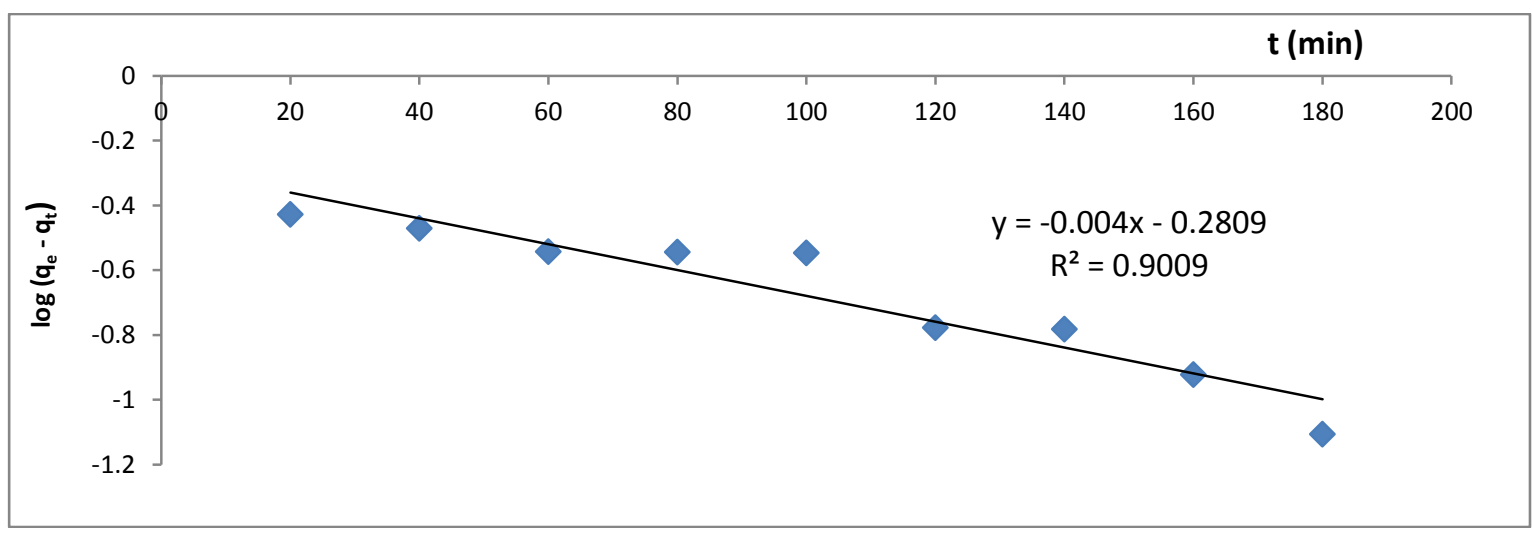

Fig 7: Pseudo-first order kinetic plot for the adsorption of crystal violet onto BP 


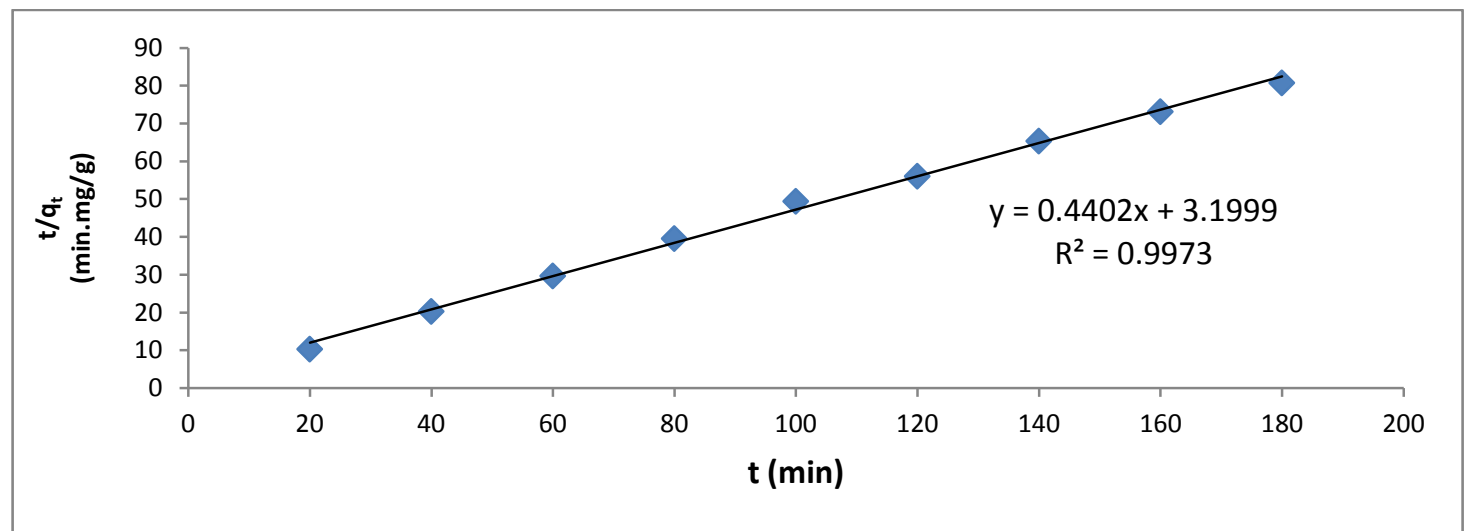

Fig 8: Pseudo-second order kinetic plot for the adsorption of crystal violet onto BP

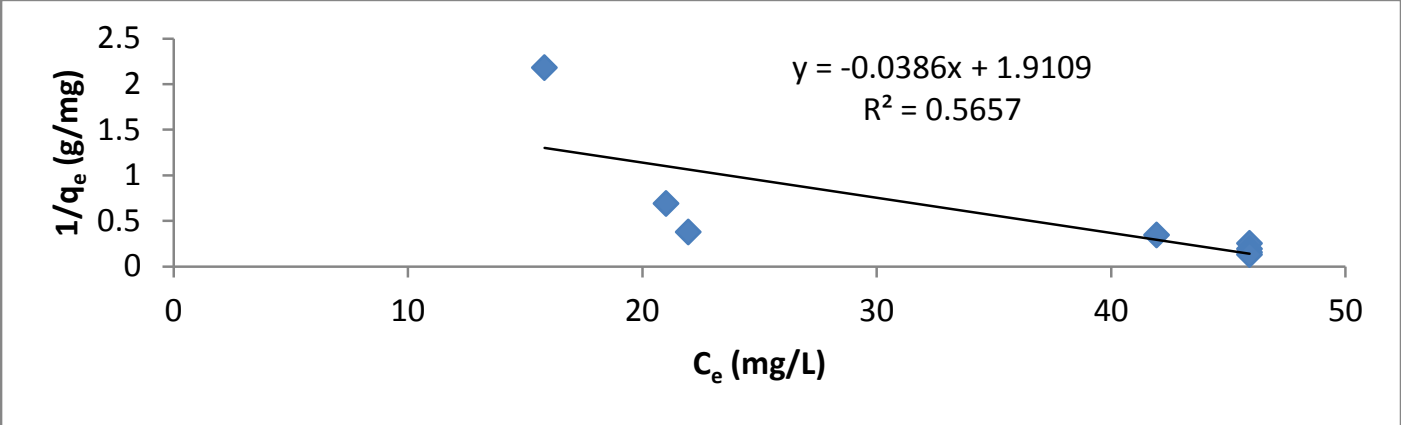

Fig 9: Langmuir isotherm for crystal violet adsorption on GS

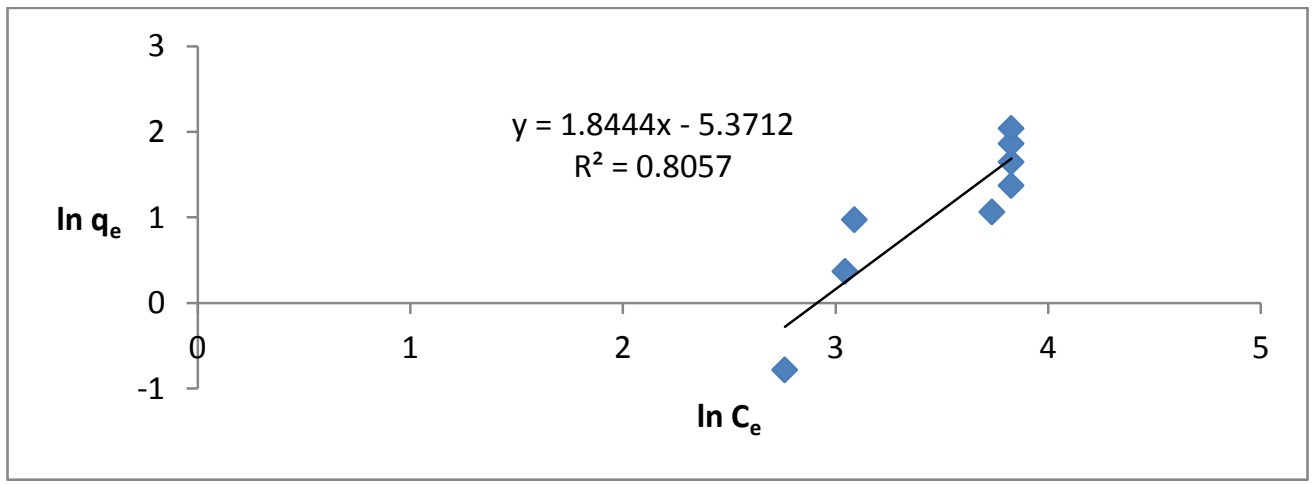

Fig 10: Freundlich isotherm for crystal violet adsorption on GS

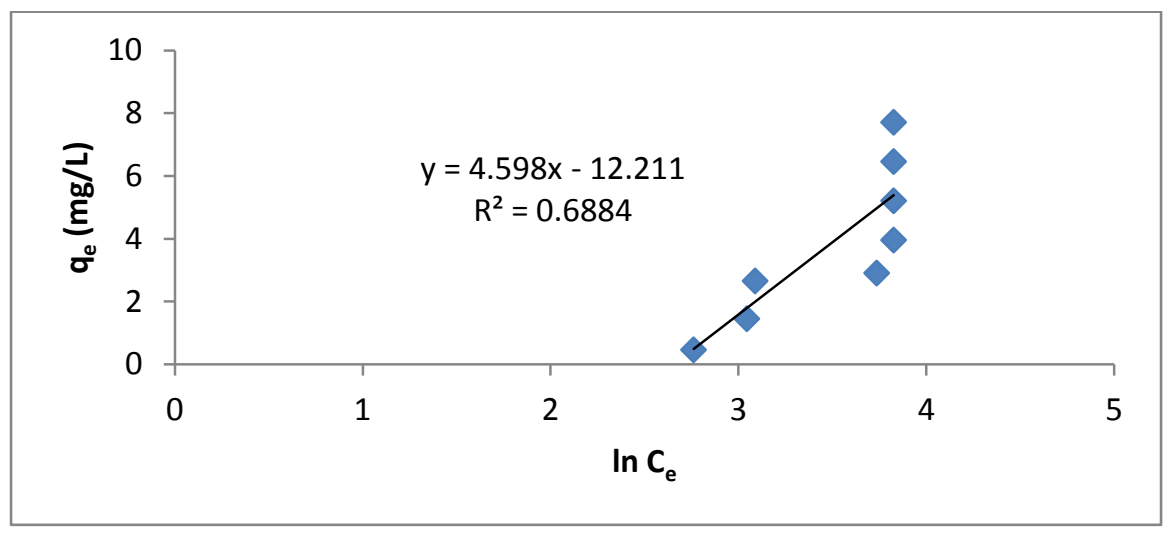

Fig 11: Temkin isotherm for crystal violet adsorption on GS 


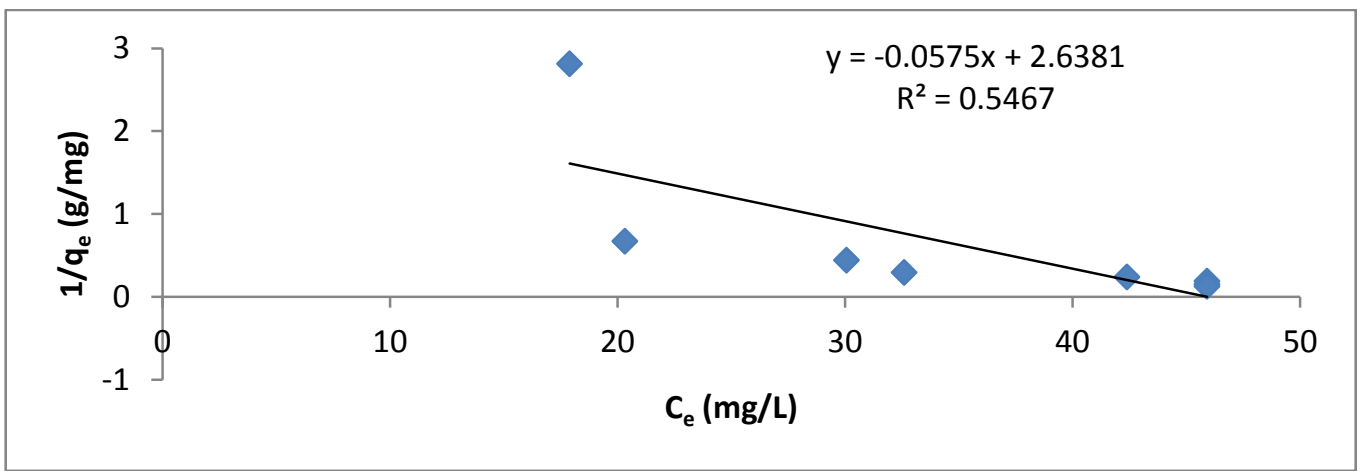

Fig 12: Langmuir isotherm for crystal violet adsorption on BP

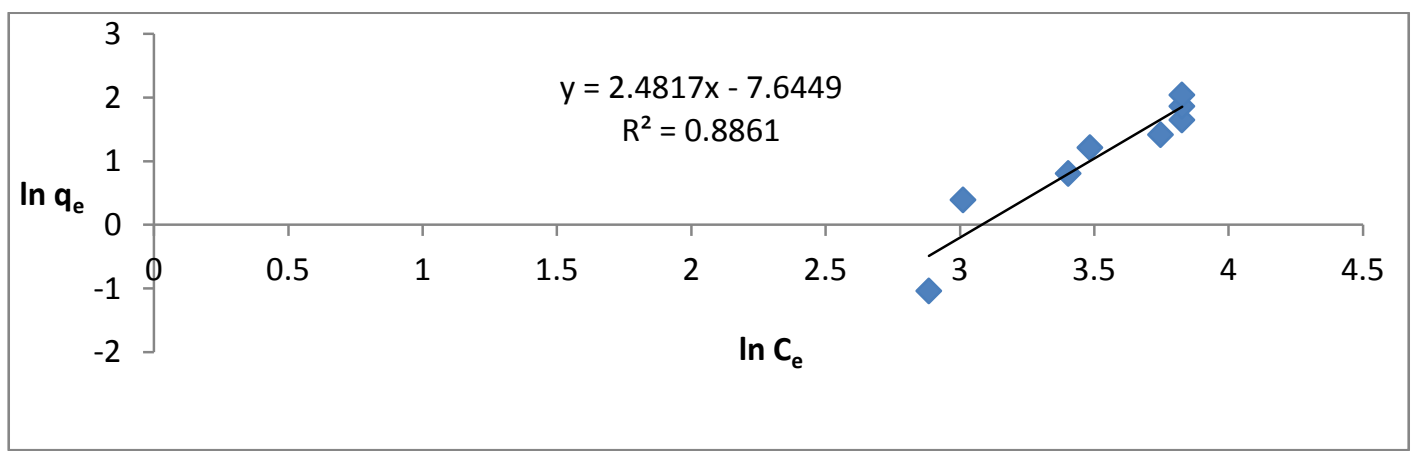

Fig 13: Freundlich isotherm for crystal violet adsorption on BP

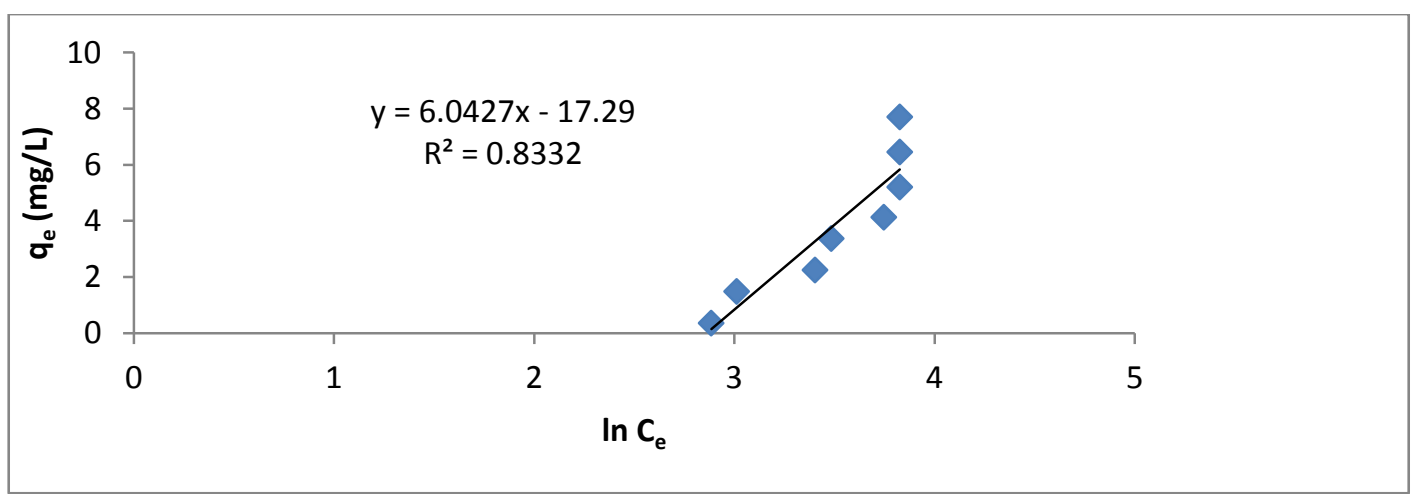

Fig 14: Temkin isotherm for crystal violet adsorption on BP

Table 1: Rate constants and coefficients of determination for the adsorption of crystal violet onto GS and BP

\begin{tabular}{ccccccc}
\hline & \multicolumn{2}{c}{$\begin{array}{c}\text { Intraparticle } \\
\text { diffusion model }\end{array}$} & \multicolumn{2}{c}{$\begin{array}{c}\text { Pseudo-first } \\
\text { order model }\end{array}$} & \multicolumn{3}{c}{$\begin{array}{c}\text { Pseudo-second } \\
\text { order model }\end{array}$} \\
\hline Adsorbent & $k_{\text {int }}$ & $R^{2}$ & $k_{1}$ & $R^{2}$ & $k_{2}$ & $R^{2}$ \\
GS & $1.32 \times 10^{-1}$ & 0.553 & $2.51 \times 10^{-1}$ & 0.747 & $6.72 \times 10^{-3}$ & 0.804 \\
BP & $3.20 \times 10^{-2}$ & 0.912 & $9.21 \times 10^{-3}$ & 0.900 & $6.05 \times 10^{-2}$ & 0.997 \\
\hline
\end{tabular}

Table 2: Equilibrium isotherm constants and coefficients of determination for the adsorption of crystal violet onto GS and BP

\begin{tabular}{cccccccccc}
\hline & \multicolumn{4}{c}{ Langmuir isotherm } & \multicolumn{2}{c}{ Freundlich isotherm } & \multicolumn{3}{c}{ Temkin isotherm } \\
\hline Adsorbent & $q_{\max }$ & $\mathrm{b}$ & $R^{2}$ & $K_{F}$ & $\mathrm{n}$ & $R^{2}$ & $K_{T}$ & $B_{1}$ & $R^{2}$ \\
GS & 0.524 & -0.02 & 0.565 & $4.65 \times 10^{-3}$ & 0.542 & 0.805 & $7.03 \times 10^{-2}$ & 4.598 & 0.688 \\
BP & 0.380 & -0.02 & 0.546 & $4.79 \times 10^{-4}$ & 0.403 & 0.886 & $5.72 \times 10^{-2}$ & 6.042 & 0.833 \\
\hline
\end{tabular}

Conclusion: Understanding the performance characteristics of an adsorbent requires, among other things, the study of its sorption kinetics and equilibrium isotherms. In this study, the suitability of 
adsorbents derived from groundnut shell and bean pod for the removal of crystal violet in aqueous solution was evaluated in a series of batch experiments. The results of these experiments revealed that the adsorption of crystal violet by both groundnut shell and bean pod involves some forms of chemical interactions between the surfaces of the adsorbents and the adsorbate. The adsorption of crystal violet on the adsorbents was also found not to reach a plateau as the concentration of adsorbate in solution increases. This study demonstrates that adsorbents derived from groundnut shell and bean pod are suitable for removing crystal violet from contaminated wastewater.

Acknowledgments: The authors wish to acknowledge the support provided by the technical staff of Biochemistry and Chemistry Laboratories in Bauchi State University, Gadau.

\section{REFERENCES}

Abia, A.A. and Asuque, E.D. (2008): Sorption of $\mathrm{Pb}(\mathrm{II})$ and $\mathrm{Cd}(\mathrm{II})$ Ions onto Chemically Unmodified and Modified Oil Palm Fruit Fibre Adsorbent: Analysis of Pseudo Second Order Kinetic Models. Indian Journal of Chemical Technology 15, 341-348.

Adinew, B. (2012): Textile Effluent Treatment and Decolorization Techniques: A Review. Chemistry: Bulgarian Journal of Science Education 21(3): 434 - 456.

Ajmal, M.; Rao, R.A.K.; Ahmad, J. and Ahmad, R. (2006): The Use of Testa of Groundnut Shell (Arachis hypogea) for the Adsorption of Ni (II) from the Aqueous System. Journal of Environmental Science and Engineering 48(3): $221-224$.

Allen, S.J. and Koumanova, B. (2005): Decolourization of Water/Wastewater Using Adsorption (Review). Journal of the University of Chemical Technology and Metallurgy 40(3): 175 $-192$.

Azmi, W.; Sani, R.K.; and Banerjee, U.C. (1998): Biodegradation of Triphenylmethane Dyes. Enzymes and Microbial Technology 22: 185 191.

Banerjee, K.; Ramesh, S.T.; Gandhimathi, R.; Nidheesh, P.V. and Bharathi, K.S. (2012): A Novel Agricultural Waste Adsorbent, Watermelon Shell for the Removal of Copper from Aqueous Solution. Iranica Journal of Energy \& Environment 3(2): 143 - 156.
Bhatnagar, A. and Minocha, A.K. (2006): Conventional and Non-Conventional Adsorbents for Removal of Pollutants from Water: A Review. Indian Journal of Chemical Technology $13,203-217$.

Carmen, Z. and Daniela, S. (2012): Textile Organic Dyes: Characteristics, Polluting Effects and Separation/Elimination Procedures from Industrial Effluents: A Critical Overview. In Puzyn, T. and Mostrag-Szlichtyng, A. (Eds) Organic Pollutants Ten Years After the Stockholm Convention: Environmental and Analytical Update. InTech, Croatia. P.55

Chen, Y.M.; Tsao, T.M. and Wang, M.K. (2011): Removal of Crystal Violet and Methylene Blue from Aqueous Solution using Soil Nano-Clays. International Conference on Environment, Science and Engineering 8, 252 - 254.

Chinniagounder, T.; Shanker, M. and Nageswaran, S. (2011): Adsorptive Removal of Crystal Violet Dye Using Agricultural Waste Cocoa (theobroma cacao) Shell. Research Journal of Chemical Sciences 1(7): $38-45$.

Choudhury, T.R.; Pathan, K.M.; Amin, M.N.; Ali, M.; Quraishi, S.B. and Mustafa, A.I. (2012): Adsorption of Cr (III) from Aqueous Solution by Groundnut Shell. Journal of Environmental Science and Water Resources 1(6): 144 - 150.

de Sousa, M.L.; de Moraes, P.B.; Lopes, P.R.M.; Montagnolli, R.N.; de Angelis, D.F. and Bidoie, E.D. (2012): Contamination by Remazol Red Brilliant Dye and its Impact in Aquatic Photosynthetic Microbiota. Environmental Management and Sustainable Development 1(2): $129-138$.

De Souza, J.V.T.M.; Diniz, K.M.; Massocatto, C.L.; Tarley, C.R.T.; Caetano, J. and Dragunski, D.C. (2012): Removal of $\mathrm{Pb}(\mathrm{II})$ from Aqueous Solution with Orange Sub-Products Chemically Modified as Biosorbent. BioResources 7(2): 2300 -2318 .

Fayoumi, L.M.A.; Ezzedine, M.A.; Akel, H.H. and El Jamal, M.M. (2012): Kinetic Study of the Degradation of Crystal Violet by $\mathrm{K}_{2} \mathrm{~S}_{2} \mathrm{O}_{8}$ : Comparison with Malachite Green. Portugaliae Electrochimical Acta 30(2): 27 - 34. 
Foo, K.Y. and Hameed, B.H. (2010): Insight into the Modeling of Adsorption Isotherm Systems. Chemical Engineering Journal 156, 2-10.

Gandhimathi, R.; Ramesh, S.T.; Sindhu, V. and Nidheesh, P.V. (2012): Single and Tertiary System Dye Removal from Aqueous Solution Using Bottom Ash: Kinetic and Isotherm Studies. Iranica Journal of Energy \& Environment 3(1): $52-62$.

Gong, Z.; Tang, C.; Tang, L. and Cheng, J. (2011): Removal of Cadmium from Aqueous Solution by Adsorption on Peanut Shell. Advances in Biomedical Engineering vol. 3-5: 190 - 194.

Grassi, M.; Kaykioglu, G.; Belgiorno, V. and Lofrano, G. (2012): Removal of Emerging Contaminants from Water and Wastewater by Adsorption Process. In Lafrano, G. (Ed) Emerging Compounds Removal from Wastewater: Natural and Solar Based Treatment. P. $15-37$.

Gursahani, Y.H. and Gupta, S.G. (2011): Decolourization of Textile Effluent by a Thermophilic Bacteria Anoxybacillus rupiensis. Journal of Petroleum \& Environmental Biotechnology 2(2): 1 -4.

Gusmao, K.A.G.; Gurgel, L.V.A.; Melo, T.M.S. and Gil, L.F. (2013): Adsorption Studies of Methylene Blue and Gentian Violet on Sugarcane Bagasse Modified with EDTA dianhydride (EDTAD) in Aqueous Solutions: Kinetic and Equilibrium Aspects. Journal of Environmental Management 118, $135-143$.

Ho, Y. (2006): Review of Second-Order Models for Adsorption Systems. Journal of Hazardous Materials B136, 681-689.

Kiran, B.M.; Srikantaswamy, S.; Pallavi, H.V.; Manoj, V. and Tasneem, T. (2013): A Study on Utilization of Groundnut Shell as Biosorbant for Heavy Metals Removal. Journal of Environmental Science, Computer Science and Engineering \& Technology 2(1): 173 - 186.

Kunjadia, P.D.; Patel, F.D.; Nagee, A. Mukhopadhyaya, P.N. and Dave, G.S. (2012): Crystal Violet (Triphenylmethane Dye) Decolorization Potential of Pleurotus ostreatus (MTCC 142). BioResources 7(1): 1189 - 1199.
Limousin, G.; Gaudet, J.P.; Charlet, L.; Szenknect, S.; Barthes, V. and Krimissa, M. (2007): Sorption Isotherms: A Review on Physical Bases, Modeling and Measurement. Applied Geochemistry 22, $249-275$.

Lin, Y.; He, X.; Han, G.; Tian, Q. and Hu, W. (2011): Removal of Crystal Violet from Aqueous Solution Using Powdered Mycelial Biomass of Ceriporia lacerata P2. Journal of Environmental Sciences 23(12): 2055 - 2062.

Mahmoud, D.K.; Mohd-Salleh, A.M. and Abdulkarim, W.A.W. (2012): Characterization and Evaluation of Agricultural Solid Wastes as Adsorbents: A Review. Journal of Purity, Utility Reaction and Environment 1(9): 451 - 459.

Mohammed, Y.; Etonihu, A.C. and Tsaku, V.A. (2011): Haxamethylpararosalinine Chloride (Crystal Violet) Oxidation by Chlorate Ions in Aqueous Acidic Medium: Kinetic Approach to the Mechanism of Reaction. Trakia Journal of Sciences 9(2): $1-7$.

Nidheesh, P.V.; Gandhimathi, R.; Ramesh, S.T. and Anantha-Singh, S.T. (2011): Investigation of Equilibrium and Thermodynamic Parameters of Crystal Violet adsorption onto Bottom Ash. Journal of International Environmental Application \& Science 6(4): $461-470$.

Nidheesh, P.V.; Gandhimathi, R.; Ramesh, S.T. and Ananthal-Singh, T.S. (2012a): Adsorption and Desorption Characteristics of Crystal Violet in Bottom Ash Column. Journal of Urban and Environmental Engineering 6(1): 18 - 29.

Nidheesh, P.V.; Gandhimathi, R.; Ramesh, S.T. and Ananthal-Singh, T.S. (2012b): Kinetic Analysis of Crystal Violet Adsorption onto Bottom Ash. Turkish Journal of Engineering and Environmental Sciences 36: 249-262.

Oluwaseye, A.; Uzairu, A. and Eddy, N.O. (2011): Biosorption of $\mathrm{Cr}$ (VI) and $\mathrm{Ni}$ (II) from Aqueous Solution onto Bacillus subtillis Immobilized in Agarose Gel. Der Chemica Sinica 2(5): 173 188.

Oranusi, N.A. and Ogugbue, C.J. (2005): Effect of Cosubstrates on Primary Biodegradation of Triphenylmethane Dyes by Pseudomonas. African Journal of Applied Zoology \& Environmental Biology 7: 38 - 44 
Ovejero, G.; Rodriguez, A.; Vallet, A. and Garcia, J. (2012): Intermediary Products in the Catalytic Wet Air Oxidation of Crystal Violet with $\mathrm{Ni} / \mathrm{MgAlO}$ as Catalyst. Industrial \& Engineering Chemistry Research 51(35): 11367 - 11372.

Pandian, G.V.; Jayaraj, R.; Srinivasan, A.P.; Deva, P.M.P. and Selvamathan, S. (2012): Adsorption Efficiency of Crystal Violet Dye onto Sludge (Effluent) Obtained from Caustic Industries. International Journal of Research in Chemistry and Environment 2(1): $265-269$.

Patil, K.K. (2011): Kinetics and Mechanism of Oxidation of Crystal Violet by Oxone. Der Chemica Sinica 2(6): 245 - 249.

Patil, S.; Deshmukh, V.; Renukdas, S. and Patel, N. (2011): Kinetics of Adsorption of Crystal Violet from Aqueous Solution Using Different Natural Materials. International Journal of Environmental Sciences 1(6): 1116 - 1134.

Patil, A.K. and Shrivastava, V.S. (2012): Kinetics and Equilibrium Studies on the Adsorption of Crystal Violet Dye Using Leucaena leucocephala (Subabul) Seed Pods as an Adsorbent. Journal of Applied Chemical Research 6(4): 24 - 36.

Prasad, A.L. and Santhi, T. (2012): Adsorption of Hazardous Cationic Dyes from Aqueous Solution onto Acacia nilotica Leaves as an Eco-Friendly Adsorbent. Sustainable Environment Research 22(2): $113-122$.

Rammel, R.S.; Zatiti, S.A. and El-Jamal, M.M. (2011): Biosorption of Crystal Violet by Chaetophora elegans alga. Journal of the University of Chemical Technology and Metallurgy 46(3): $283-292$.

Rashed, M.N. (2013): Adsorption Technique for the Removal of Organic Pollutants from Water and Wastewater. In Rashed, M.N. (Ed) Organic Pollutants: Monitoring, Risk and Treatment. InTech. Croatia. P.185

Ratna, P.S. and Padhi, P.S. (2012): Pollution Due to Synthetic Dyes Toxicity \& Carcinogenicity Studies and Remediation. International Journal of Environmental Science 3(3): 940 - 955.
Sharma, N.; Tiwari, D.P. and Singh, S.K. (2012): Decolourisation of Synthetic Dyes by Agricultural Waste: A Review. International Journal of Scientific \& Engineering Research 3(2): $1-10$.

Shouman, M.A.; Khedr, S.A. and Attia, A.A. (2012): Basic Dye Adsorption on Low Cost Kinetic and Equilibrium Studies. IOSR Journal of Applied Chemistry 2(4): $27-36$.

Sposito, G. (2004): The Surface Chemistry of Natural Particles. Oxford University Press. Oxford. P.25 Su, C. and Wang, Y. (2011): Influence Factors and Kinetics on Crystal Violet Degradation by Fenton and Optimization Parameters Using Response Surface Methodology. International Conference on Environmental and Agricultural Engineering 15: $76-80$.

The council of Pharmaceutical Society of Great Britain (1973): British Pharmaceutical Codex. The Pharmaceutical Press. London. P.134

Thorat, P.R. and Sayyad, M. (2010): Microbial Decolourization and Degradation of Crystal Violet by Aerobic Bacteria. The Bioscan 5(4): $591-594$.

Tom-Sinoy, E.S.; Mohan, D.A. and Shaikh, H. (2011): Biodegradation of Textile Dyes by Pseudomonas Species and E. Coli. VSRD Technical and Non-Technical Journal 2(5): 238 248.

Zablocka-Godlewska, E.; Przytas, W. and GrabinskaSota, E. (2009): Decolourization of Triphenylmethane Dyes and Ecotoxicity of their End Products. Environment Protection Engineering 35(1): 161 - 169.

Zhang, Z.; Moghaddam, L.; O’Hara, I.M. and Doherty, W.O.S. (2011): Congo Red Adsorption by Ball-Milled Sugarcane Bagasse. Chemical Engineering 178, $122-128$. 